\title{
Five new species of the genus Sphelodon (Hymenoptera: Ichneumonidae) from Brazil with a key to the Neotropical species
}

\author{
Andrés Herrera \& Angélica Penteado-Dias \\ Departamento de Ecologia e Biologia Evolutiva, Universidade Federal de São Carlos, Rod. Washington Luís, km 235, \\ CEP 13565-905, São Carlos, SP, Brasil; andresfhf@gmail.com, angelica@ufscar.br
}

Received 17-VIII-2010. C Corrected 14-IV-2011. Accepted 10-V-2011.

\begin{abstract}
The parasitoid wasp family Ichneumonidae currently includes approximately 37 subfamilies worldwide. Banchinae subfamily is a cosmopolitan group with three tribes: Atrophini, Banchini and Glyptini, this last characterized with oblique grooves on tergites II-IV, a dorsal subapical notch on the ovipositor, and a median apical impression in the subgenital plate. From the latter tribe, the genus Sphelodon, with eight species reported, can be recognized for the presence of a prominent basolateral tooth in the first abdominal tergite. Significant previous comprehensive studies for that group have been done in Costa Rica by local and international experts, but it is highly probable that many species remain undescribed in the region; before this survey, only one species (S. annulicornis) was registered from Brazil. The material reviewed in this study was obtained from main entomological collections of Southeast and South Brazil, from localities corresponding to 17 of the 27 States of the country, although most of the specimens (70.3\%) were collected in São Paulo State. Approximately 3000 specimens of the subfamily have been examined, 29 belonging to Sphelodon. The description format in this work broadly follows previous works; the species were illustrated through SEM in low vacuum mode (without uncoated the specimens). Here five new species of the genus Sphelodon are described and illustrated, one of these (S. brunicornis), differs from the rest of the species by lacking a median band in the flagellum. An identification key to the Neotropical species is provided. Rev. Biol. Trop. 59 (4): 1621-1635. Epub 2011 December 01.
\end{abstract}

Key words: Glyptini, identification key, South America, taxonomy, wasps.

The Banchinae is a cosmopolitan group of Ichneumonidae characterized by having a long, apically notched ovipositor, a propodeum without or with only a few carinae, a tergite I with spiracles located around or before the centre (except in the genus Lissocaulus) and frequently, the anterior part of the submetapleural carina expanded into a broad lobe (Gauld et al. 2002). This subfamily comprises three tribes: Atrophini, Banchini and Glyptini; the latter can be certainly distinguished from the two other tribes of Banchinae by the possession of oblique grooves on tergites II-IV. Such a sculpture (at least one similar) can also be found in all members of the subfamily Lycorininae and in some few of Pimplinae (Gauld et al. 2002), and for that reason it is not completely reliable to recognize any ichneumonid as a Glyptini. Nevertheless, both lycorinines and pimplines lack a dorsal subapical notch on the ovipositor and a median apical impression in the subgenital plate (founded in all members of Glyptini) (Gauld et al. 2002). The tribe Glyptini comprises twelve genera worldwide and five genera in the Neotropical region: Levibasis Townes from Peru, Teleutaea Förster with a single Neotropical species from Mexico, Glypta Gravenhorst with species registered in the Neotropics from Mexico, Costa Rica, Uruguay and Argentina, Zaglyptomorpha Viereck a genus restricted to the New World and Sphelodon Townes from North America, Mexico, Costa Rica, Panama, 
Venezuela and Brazil (Yu \& Horstmann 1998, Gauld et al. 2002, Yu et al. 2005). Most of Sphelodon species have a flagellum with a median whitish band, but this is also present in Levibasis (Townes, 1970). They usually lack both carinae in frons and vein $3 r s-m$ in fore wing. Nevertheless, the main diagnostic feature of Sphelodon is its first abdominal tergite with a prominent basolateral tooth, giving this genus its name (i.e. sphelas= pedicel, plus odons $=$ tooth); that tooth is absent in other Glyptini. The genus Sphelodon Townes, 1966 currently includes, eight New World species (Yu \& Horstmann 1998, Yu et al. 2005); three of them are exclusively Nearctic: $S$. beameri Dasch, 1988, S. concolor Dasch, 1988, and $S$. nomene (Davis, 1988); four have a Neotropical distribution: S. guanacastensis Godoy \& Gauld 2002, S. ugaldei Godoy \& Gauld 2002, S. wardae Godoy \& Gauld 2002, which are so far only known from Costa Rica, and S. annulicornis (Morley, 1914), which is the only species of this genus previously recorded from Brazil, but it is also known from Mexico (Townes \& Townes 1966, Ruiz et al. 2002) and Costa Rica, suggesting that it is likely distributed throughout the Neotropical region (Gauld et al. 2002). The remaining species, S. phoxopteridis (Weed, 1888), is found in both the Nearctic and Neotropical regions (Dasch 1988, Yu \& Horstmann 1998, Gauld et al. 2002, Ruiz et al. 2002, Yu et al. 2005, Ruiz 2010). The only host records for any species of the genus Sphelodon are from the Nearctic region, where the known hosts include the lepidopterous families Oecophoridae, Pyralidae and Tortricidae (Dasch 1988, Gauld et al. 2002, Ruiz 2010). Here five new species of Sphelodon are described from Brazil and a key provided.

\section{MATERIAL AND METHODS}

The material analyzed was obtained from the main entomological collections of Southeastern and Southern Brazil: Departamento de Ecologia e Biologia Evolutiva, Universidade Federal de São Carlos, São Carlos, SP, Brasil (DCBU), Universidade Federal de Paraná
(UFPR), Museu de Zoologia Universidade de São Paulo (MZUSP), Universidade Federal de Espírito Santo (UFES), Universidade Federal de Rio de Janeiro (UFRJ), Coleção Entomológica Instituto Oswaldo Cruz (CEIOC), and from the Project Biota Noroeste UNESP São José de Rio Preto (UNESP-SJRP). More than 3000 specimens of the subfamily Banchinae were reviewed, 29 corresponding to the genus Sphelodon.

The nomenclature treatment, morphological terminology and taxonomic characters used here follow Gauld (1991) and Gauld et al. (2002). The new species treated in this study were compared with the descriptions included in Gauld et al. (2002), through comparison with the original descriptions or with several images of some Holotypes. Data from Morley (1914), Dasch (1988) and Gauld et al. (2002) have been used here to produce the key for the Neotropical Sphelodon species. The main striking characteristics of each described species were illustrated through a SEM (FEI Quanta 250) in low vacuum mode; with this technique the specimens do not require to be uncoated. Digital photographs were taken in stereomicroscope with Leica Software. Some images (photographs and drawings) extracted from Gauld et al. (2002) are used here with permission of the authors to integrate the key for the neotropical species of Sphelodon with the suitable acknowledgements.

\section{Sphelodon boraceiensis Herrera n. sp.}

(Figs. 1, 8, 11, 16, 21)

Diagnosis: This species differs from $S$. annulicornis in its propodeal characteristics (with an enclosed area superomedia in S. annulicornis and without an enclosed area superomedia in S. boraceiensis n. sp. (Fig. 11)) and in the color pattern (e.g. propodeum pale yellow anteriorly with a transverse black band in $S$. annulicornis and orange in S. boraceiensis). It differs from $S$. wardae in the pronotum (in dorsal view with upper end of epomia forming a distinct tubercle in $S$. wardae, not tuberculate in S. boraceiensis) and also in its propodeal 

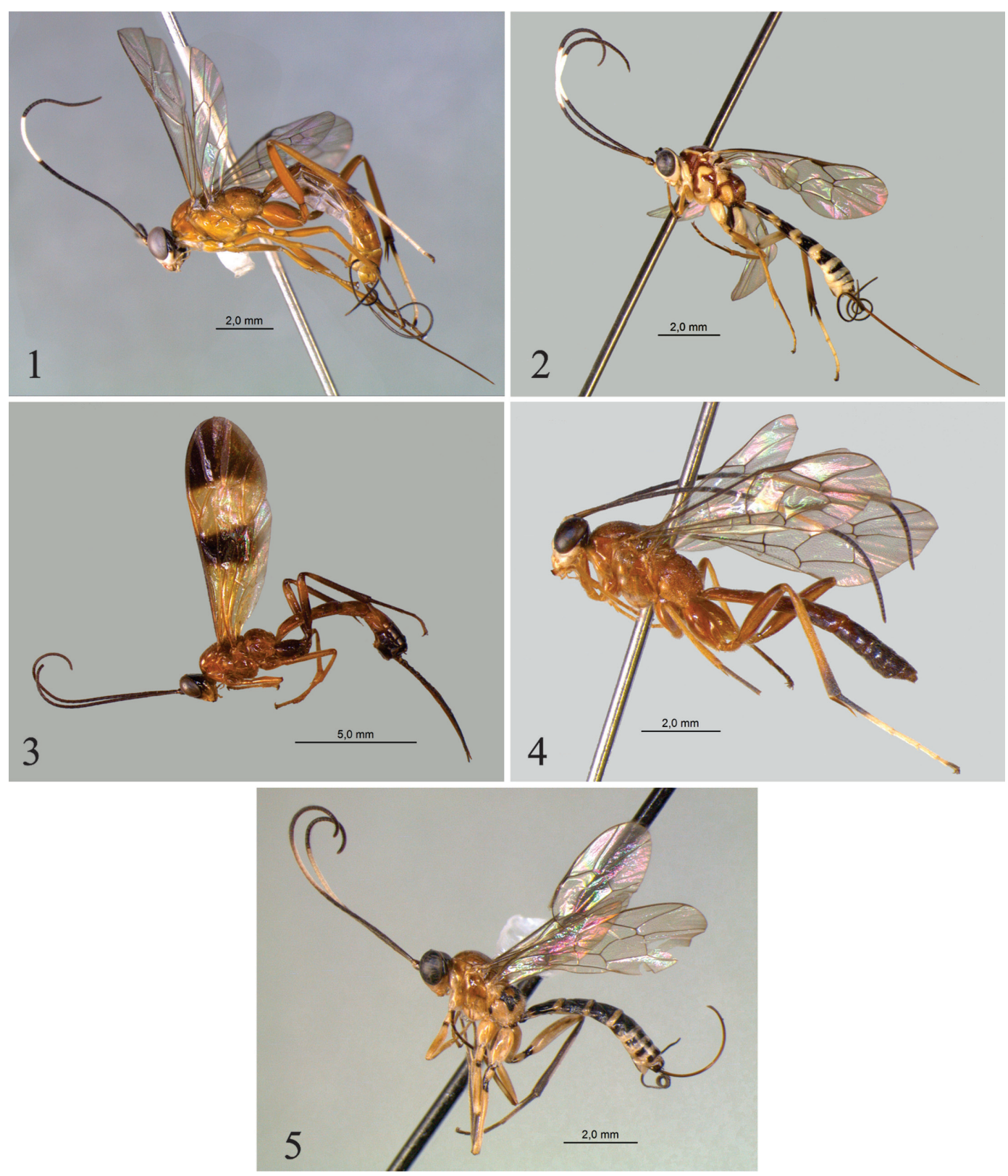

Figs. 1-5. Sphelodon spp., habitus; 1, Sphelodon brunicornis n. sp.; 2, Sphelodon boraceiensis n. sp.; 3, Sphelodon zuleidei n. sp.; 4, Sphelodon plaumanni n. sp.; 5, Sphelodon botucatensis n. sp. 

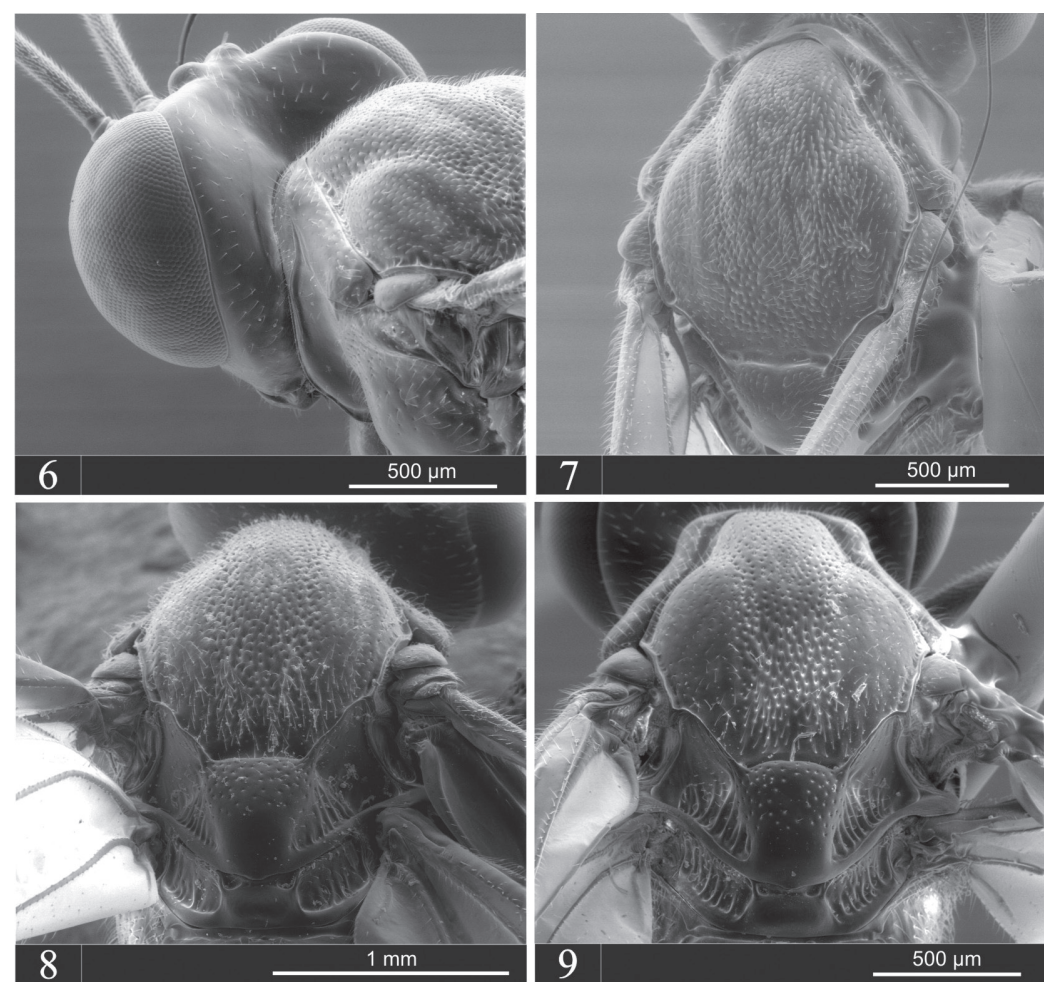

Figs. 6-9. Stereoscan photographs of Sphelodon spp. Fig. 6, Sphelodon zuleidei n. sp, Head (posterior), and anterior part of mesoscutum. Figs. 7-9. Mesoscutum; 7, Sphelodon zuleidei n. sp.; 8, Sphelodon boraceiensis n. sp.; 9, Sphelodon botucatensis $\mathrm{n} . \mathrm{sp}$.

characteristics (with an enclosed area superomedia in $S$. wardae). It differs from $S$. guanacastensis in the mesopleuron which has some sparse setiferous punctures in $S$. boraceiensis, whilst $S$. guanacastensis has a closely and coarsely punctate mesopleuron. It differs from S. phoxopteridis in the color pattern (e.g. metasoma mostly black with transverse pale yellow bands in $S$. phoxopteridis, and orange in $S$. boraceiensis) and in lacking an occipital carina, while in S. phoxopteridis the lower end of the occipital carina is present. It differs from $S$. ugaldei in color pattern (e.g. gena and vertex yellow in $S$. ugaldei and black in S. boraceiensis). It differs from $S$. plaumanni n. sp. in the color pattern (e.g. face white with a black spot in $S$. boraceiensis and dull yellow in S. plaumanni), and in several aspects (e.g. terguites I and II with somewhat sinuous oblique grooves, and posterior margin of area basalis concave in $S$. boraceiensis and S. plaumanni with rather straight oblique grooves and a posterior part of area basalis sort of straight, nor convex, nor concave). This species differs from the nearctic species $S$. beameri in its color pattern (mostly orange in $S$. boraceiensis, mostly rufous in $S$. beameri, with a white band between flagellomeres 12 and 21 in S. boraceiensis, with a pale yellow band on flagellar segments 13-18 in $S$. beameri). It differs from the nearctic species $S$. concolor in number of flagellomeres (44 in S. boraceiensis, 37 in S. concolor) and in the color pattern (e.g. flagellar segments 14-15 weak pale in the latter species). It differs from the nearctic species $S$. nomene in propodeal characteristics (without an enclosed area superomedia in $S$. boraceiensis and with an enclosed one in S. nomene). 
Holotype: Female: Fore wing length $7.6 \mathrm{~mm}$; hind wing length $5.3 \mathrm{~mm}$. Clypeus $1.3 \mathrm{x}$ as broad as long; lower face with a weak median swelling; malar space $0.8 \mathrm{x}$ as long as basal mandibular width; frons flat and smooth; occipital carina absent; head in dorsal view with gena very strongly constricted behind eyes, flat. Antenna with 44 flagellomeres. Pronotum long, slightly swollen above upper end of epomia, epomia itself long and very strong, mesoscutum centrally rather finely and sparsely punctate with hairs, laterally weakly punctulate with setae; notauli present but weak and shallow; mesopleuron with sparse fine setiferous punctures; epicnemial carina rather straight, not reaching anterior margin of mesopleuron and exceeding level of lower corner of pronotum; sternal part of mesothorax $1.2 \mathrm{x}$ as long as mid coxa. Metapleuron uniformly punctate with hairs, and with a weak to strong stria at posterior margin of submetapleural carina. Pleural carina complete (Fig. 11); propodeum with posterior transverse carina complete, strong and sinuous, anterior transverse carina complete and strong, lateral and lateromedian longitudinal carinae present from anterior margin to spiracle level, then with small vestiges (Fig. 11). Fore tibia with spur normally developed, $2.3 \mathrm{x}$ as long as breadth of tibia; mid tibia without conspicuous denticles on outer surface, and with spurs nearly equal, longer $1.2 x$ length of shorter. Fore wing with abscissa of $C u 1$ between $1 \mathrm{~m}$-cu and $C u 1 \mathrm{a} 2.0 \mathrm{x}$ as long as $C u 1 \mathrm{~b}$; hind wing with length of abscissa of $C u 1$ between $M$ and $c u-a$ $0.6 \mathrm{x}$ as long as combined lengths of this vein and $\mathrm{cu}-\mathrm{a}$. Metasoma (Fig. 16) with tergite I smooth, with lateromedian longitudinal carinae weak, present on anterior 0.2 ; tergite $\mathrm{I}$ in lateral view with spiracle positioned anterior to centre, about 0.3 of way along, base with sharp lateral tooth, with margin pointing down (Fig. 21 ); tergite II 1.1 as long as posteriorly broad, with oblique grooves strongly impressed, with central triangular area smooth, lateral area smooth with some pubescence; tergites III-IV similar though latter with oblique grooves very weak, almost vestigial. Ovipositor of moderate length, 1.6x as long as hind tibia.
Coloration: Head with face mostly white with medium longitudinal brown spot; clypeus white, mandibles white with apex light brown; antenna ventrally with margin of scape and pedicel white, flagellomeres black with flagellomeres 12-21 white, flagellomeres 11 and 22 light brown. Gena, frons black, vertex with two yellow spots parallel to posterior ocelli and very close to eyes; labial and maxilar palps yellow. Mesosoma mostly orange, mesoscutum with two ferruginous spots (submedial one bigger than posterior one); propleuron, mesopleuron and metapleuron light orange. Wings hyaline with pterostigma brown. Fore legs light orange with tarsus infuscate, mid legs orange, with tarsus light brown, hind legs with coxa, trochanter and trochantellus orange, with tibia orange, with apex ferrugineous; tarsus mostly white, with tarsomere 1 ferruginous at base, tarsomere 5 mostly ferruginous. Metasoma orange, with triangular area of tergites II-IV orange ferruginous. Ovipositor orange; ovipositor sheaths dark brown, with apex brown.

Variation: Two female from the same locality have a dark orange mesosoma, and a dark brown metasoma; besides these, one of those two female (29.IV-21.V.2008) has the flagellomeres 13-21 white; the other female (28. VI-02.VIII. 2008) has the flagellomeres 12-20 white, posterior transverse carina less sinuous, tergite I with tooth present but rather truncated, pointing to the side.

Holotype: Female BRASIL, SP, Salesópolis, Reserva Biológica Boracéia 2339' S 4553.9' W. Trilha dos Pilões, PT.6 19-22. VI.2002 Bandejas Amarelas APAguiar \& ACCMacedo coll. BIOTA-FAPESP (MZUSP). Paratypes. 2 Females BRASIL, SP, Salesópolis, Reserva Biológica Boracéia 45 W 53.9', 23 S 39. Trilha dos Pilões, PT.4 (MZUSP). 19-22.VI.2002 Bandejas Amarelas APAguiar \& ACCMacedo coll. BIOTA-FAPESP. $45 \mathrm{~W}$ 53'51.4", 23 S 39' 03.6". Trilha dos Pilões, PT.3 9-15.I.2003 Malaise 863m ACCMacedo \& JSFreitas coll. BIOTA-FAPESP (MZUSP). 
Etymology: The specific name refers to the type-locality, the Boracéia Natural Reserve, located in the city of Salesópolis, SP, Brazil.

\section{Sphelodon botucatensis Herrera n. sp.} (Figs. 2, 9, 14, 19, 22)

Diagnosis: This species resembles $S$. annulicornis, $S$. brunicornis n. sp. and $S$. wardae in having a completely delineated area superomedia (Fig. 14). It differs from $S$. annulicornis in the number of flagellomeres and color pattern (39-40 flagellomeres in $S$. annulicornis, 43 in $S$. botucatensis n. sp.), from $S$. brunicornis n. sp. in the color of the flagellum. It differs from $S$. wardae in the color pattern and in epomia characteristics (in dorsal view with upper end of epomia forming a distinct tubercle in $S$. wardae, not tuberculate in $S$. botucatensis). This species differs from S. boraceiensis, S. phoxopteridis and $S$. ugaldei clearly in the color pattern and in propodeal characteristics (without an enclosed area superomedia in these species), and from $S$. guanacastensis in propodeum and mesopleuron characteristics (the current species has a closely and coarsely punctate mesopleuron). It differs from the species $S$. beameri and $S$. concolor in propodeal characteristics (without an enclosed area superomedia in these nearctic species and with a enclosed one in $S$. botucatensis) and from $S$. nomene (also neartic) in the color pattern (e.g. metasoma black ferruginous with transverse yellow bands in S. botucatensis, and mostly tawny-rufous in $S$.nomene).

Female: Fore wing length $6.1 \mathrm{~mm}$; hind wing length $3.5 \mathrm{~mm}$. Clypeus $1.3 \mathrm{x}$ as broad as long; lower face very weakly convex, smooth; malar space $0.8 \mathrm{x}$ as long as basal mandibular width; frons flat and smooth; occipital carina more or less entirely absent, with short vestige laterally; head in dorsal view with gena rounded behind eyes. Antenna with 43 flagellomeres. Pronotum long, not swollen above epomia, epomia itself strong but short, not reaching upper margin of pronotum; mesoscutum punctulate with setae, laterally with punctures finer and weaker; notauli present, but weak and shallow; mesopleuron mostly punctulate with setae; epicnemial carina rather sinuous, reaching anterior margin of mesopleuron, exceeding level of lower corner of pronotum; sternal part of mesothorax $1.3 \mathrm{x}$ as long as mid coxa. Metapleuron punctulate with setae, with transverse carina at posterior margin of submetapleural carina. Pleural carina complete and strong (Fig. 14); propodeum with dorsal carinae almost complete, delineating enclosed area superomedia; lateral longitudinal carina present on anterior margin until anterior transverse carina; posterior transverse carina sinuous, forming an " $M$ " shape (Fig. 14). Fore tibia with spur normally developed, $1.4 \mathrm{x}$ as long as breadth of tibia; mid tibia without conspicuous denticles on outer surface, with spurs nearly equal, longer $1.1 \mathrm{x}$ length of shorter. Fore wing with abscissa of $C u 1$ between $1 m$ - $c u$ and $C u 1 \mathrm{a}$ $1.5 \mathrm{x}$ as long as $C u 1 \mathrm{~b}$; hind wing with length of abscissa of $C u 1$ between $M$ and $c u-a 0.4 \mathrm{x}$ as long as combined lengths of this vein and $c u-a$. Metasoma (Fig. 19) with tergite I smooth with some setiferous punctures, with lateromedian longitudinal carinae very weak, in dorsal view present on anterior 0.2 ; tergite I in lateral view, with spiracle positioned anterior to centre, about 0.3 of way along; base with rather truncated lateral tooth, margin pointing laterally (Fig. 22 ); tergite II 1.0 as long as posteriorly broad, with oblique grooves strongly impressed, with central triangular area smooth, lateral area similar but with some isolated setae; tergites III-IV similar though latter with oblique grooves weaker, with some setae specially in lateral area. Ovipositor of moderate length, $1.9 \mathrm{x}$ as long as hind tibia.

Coloration: Head: face light yellow with central longitudinal brown spot, clypeus and mandible light yellow, apex of mandibles ferruginous, labial and maxilar palps light yellow; frons, vertex and occiput centrally brown ferruginous, light yellow laterally; ocelli brown ferruginous; gena mostly light yellow. Eyes dark brown. Antenna, scape brown with margin yellow, pedicel yellow. First flagellomere 
brown, flagellomeres 2-8 dark brown, flagellomere 9 mostly dark brown, flagellomeres 10-18 white, flagellomere 19 mostly white, flagellomeres 20+ dark brown. Mesosoma: mesoscutum red, scutellum yellow, dorsellum yellow; pronotum mostly red with dorsal and ventral margins yellow; mesopleuron yellow centrally, red epicnemium, dorsal margin and posterior margin; metapleuron mostly yellow, subalar prominence and tegula yellow. Wings hyaline, pterostigma brown. Propodeum mostly red with yellow spots in area dentipara. Fore legs: coxa, trochanter, trochantellus light yellow; femur tibia and tarsus orange; mid legs: coxa, trochanter light yellow, trochantellus mostly light yellow with marginal brown ferruginous spot; femur and tibia orange; tarsus brown; hind legs coxa yellow with inner and outer ferruginous spots, basal half of trochanter ferruginous, rest yellow: trochantellus with apex ferruginous: femur with inner side orange, outer side dark orange; tibia brown with base and apex ferrugineous; tarsus mostly white; tarsomere 1 with base ferruginous, tarsomere 5 ferruginous. Metasoma with tergite I black ferruginous with anterior and posterior margins yellow; tergites II-III black ferruginous with anterior corners and posterior margins yellow; tergite IV mostly black ferruginous, rest light yellow; tergite V light yellow, basal half ferruginous; tergites VIVII light yellow with anterior margin with black ferruginous strip on anterior margins. Ovipositor orange, ovipositor sheaths dark brown.

Holotype: Female BRASIL, SÃO PAULO, Botucatu, 48 W 26'41', 22 S 53'07', VIII, 1986, 804m, H.C.Almeida col. (UFPR).

Etymology: The name of this species refers to the city of Botucatu (SP, Brazil), the type-locality.

\section{Sphelodon brunicornis Herrera n. sp.} (Figs. 3, 10, 15, 20)

Diagnosis: This species differs from the other described species of the genus as the antennal flagellum lacks a median white band.
Female: Fore wing length $9.1 \mathrm{~mm}$; hind wing length $6.5 \mathrm{~mm}$. Clypeus $1.5 \mathrm{x}$ as broad as long; lower face flat and smooth; malar space $0.7 \mathrm{x}$ as long as basal mandibular width; frons flat and smooth; occipital carina dorsally centrally interrumpted, its lower end reaching hypostomal carina before mandibular base; head in dorsal view with gena very strongly constricted behind eyes, flat. Pronotum long, not swollen above epomia, the epomia itself strong but short, not reaching upper margin of pronotum; mesoscutum centrally rather finely and sparsely punctate with hairs, laterally weakly punctulate with setae; notauli quite strongly impressed anteriorly; mesopleuron polished with some sparse punctures; epicnemial carina dorsally sinuous, not reaching anterior margin of mesopleuron and exceeding level of lower corner of pronotum; sternal part of mesothorax $1.4 \mathrm{x}$ as long as mid coxa. Metapleuron uniformly finely and sparsely punctate, with a transverse stria at the anterior margin of the submetapleural carina, and a strong carina from posterior margin of submetapleural carina and apical margin of metapleuron. Pleural carina complete and strong (Fig. 10); propodeum with carinae complete and strong, delineating elongate enclosed area superomedia (Fig. 10). Fore tibia with spur normally developed, $2.2 \mathrm{x}$ as long as breadth of tibia; mid tibia without conspicuous denticles on outer surface and with spurs nearly equal, the longer $1.2 x$ length of shorter. Fore wing with abscissa of $C u 1$ between $1 m-c u$ and $C u 1 \mathrm{a} 1.7 \mathrm{x}$ as long as $C u 1 \mathrm{~b}$; hind wing with length of abscissa of $C u 1$ between $M$ and $c u-a 0.8 \mathrm{x}$ as long as combined lengths of this vein and $c u-a$. Metasoma (Fig. 15) with tergite I smooth, with lateromedian longitudinal carinae quite strong, present on anterior 0.6; tergite I in lateral view, with spiracle positioned anterior to centre, about 0.3 of way along, base with a rather rounded lateral tooth, margin pointing laterally (Fig. 20); tergite II 1.0 as long as posteriorly broad, with oblique grooves strongly impressed, with central triangular and lateral areas smooth and with some fine and sparse pubescence; tergites III-IV similar though the latter with the 


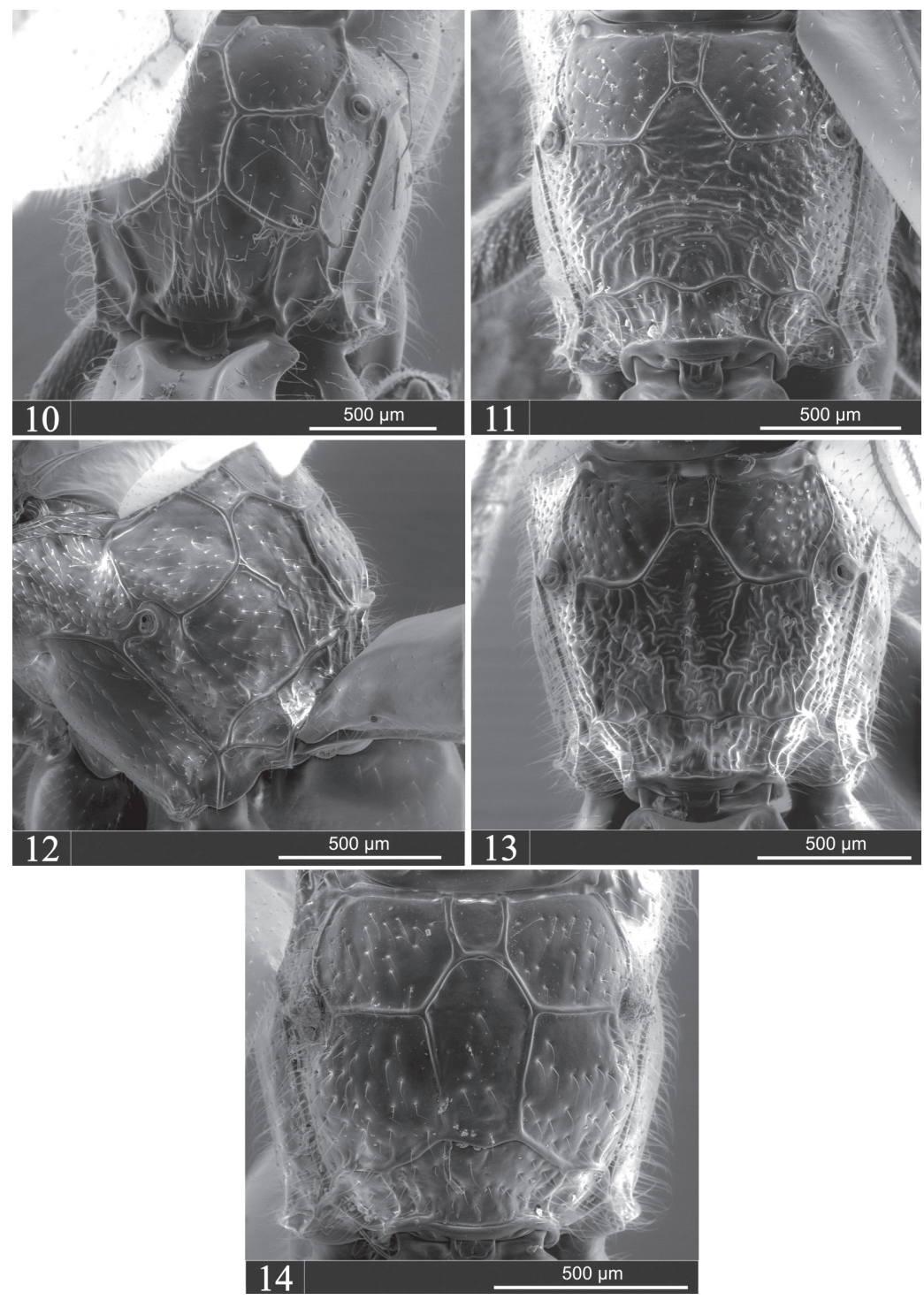

Figs. 10-14. Stereoscan photographs of Sphelodon spp., propodeum; 10, Sphelodon brunicornis n. sp.; 11, Sphelodon boraceiensis n. sp.; 12, Sphelodon zuleidei n. sp.; 13, Sphelodon plaumanni n. sp.; 14, Sphelodon botucatensis n. sp.

oblique grooves very weak, almost vestigial. Ovipositor of moderate length, $1.7 \mathrm{x}$ as long as hind tibia.

Coloration: Head mostly black. Lower face partly yellow, clypeus and mandible yellow. Apex of mandibles ferruginous. Gena posteriorly ferruginous, anteriorly surrounding area of eye dark orange. Labial and maxilar palps orange. Antenna brown, pedicel orange on dorsal margin. Mesosoma orange. Fore wing with two brown bands, one near the middle, the other at the posterior margin; pterostigma yellow; hind wing infuscate (hyaline yellow). Fore and mid legs orange, hind legs with coxa, trochanter, trochantellus and base 
of femur dark orange, tibia and tarsus light brown. Metasoma mostly orange, with tergites $\mathrm{V}+$ ferruginous. Ovipositor orange, ovipositor sheaths black.

Holotype: Female BRASIL, PA, Canindé, Rio Gurupí. IV 1963 Malkin \& Pinheiros col. (UFPR). Specimen condition: antenna incomplete (left antenna with 25 flagellomeres, right antenna with 37 flagellomeres).

Etymology: The specific name refers to the characteristic color of the antennae.

Comments: All currently described species of Sphelodon have a flagellum with a median whitish band. Although the holotype lacks some flagellomeres in both antenna, there are enough present to be certain that there is no whitish band; this is because in the rest of the described species of Sphelodon the white or yellow band is centrally located (i.e. from flagellomeres 3 (the lowest) to 21 (the uppermost)).

\section{Sphelodon plaumanni Herrera n. sp.} (Figs. 4, 13, 18, 23)

Diagnosis: This species resembles $S$. boraceiensis, S. guanacastensis, S. phoxopteridis and $S$. ugaldei in not having a delineated area superomedia (Fig. 13). It differs from $S$. guanacastensis in characteristics of the mesopleuron; the latter species has a closely and coarsely punctate mesopleuron. That of $S$. plaumanni is rather smooth. It differs from $S$. phoxopteridis in that in this species the lower end of the occipital carina is distinct, while in S. plaumanni it is absent. It differs from $S$. ugaldei in the number of flagellomeres (39-40 in $S$. ugaldei, 45 in $S$. plaumanni) and in the color pattern (e.g. gena and vertex pale yellow in $S$. ugaldei, and black in S. plaumanni). It differs from $S$. boraceiensis in the color pattern (e.g. scape and gena mainly yellow in $S$. plaumanni and scape and gena mostly black in $S$. boraceiensis) and in others features (e.g. terguite I with lateral longitudinal striae at posterior margin and lateromedian longitudinal carina, after transverse posterior carina, very weak and some straight in S. plaumanni and terguite I smooth at posterior margin and lateromedian longitudinal carina, after transverse posterior carina, strong and sinuous in $S$. boraceiensis). It differs from $S$. annulicornis, $S$. botucatensis and $S$. brunicornis, in the color pattern and propodeal characteristics (with a completely delineated area superomedia in these species). It differs from $S$. wardae in propodeum and epomia characteristics (in dorsal view with upper end of epomia forming a distinct tubercle in $S$. wardae, not tuberculate in S. plauman$n i)$. This species differs from the species $S$. beameri and $S$. concolor in the color pattern (e.g. mostly orange and flagellomeres 13-22 white in S. plaumanni and mostly rufous and flagellomeres 13-18 pale yellow in S. beameri; flagellomeres 14-15 weak pale in $S$. concolor). It differs from $S$. nomene in propodeal characteristics (without an enclosed area superomedia in the neotropical species and with an enclosed the nearctic one).

Male: Fore wing length $6.7 \mathrm{~mm}$; hind wing length $4.7 \mathrm{~mm}$. Clypeus $1.5 \mathrm{x}$ as broad as long; lower face with weak median swelling; malar space $0.7 \mathrm{x}$ as long as basal mandibular width; frons flat and smooth; occipital carina absent; head in dorsal view with gena rounded behind eyes. Antenna with 45 flagellomeres. Pronotum long, not swollen above epomia, epomia itself strong and long but not reaching upper margin of pronotum; mesoscutum uniformly punctulate with setae; notauli weakly impressed anteriorly; mesopleuron with setiferous punctures at ventral and anterior margins; epicnemial carina weakly impressed, somewhat sinuous at dorsal margin, not reaching the anterior margin of mesopleuron and exceeding level of lower corner of pronotum; sternal part of mesotho$\operatorname{rax} 1.4 \mathrm{x}$ as long as mid coxa. Metapleuron punctulate with setae and with transverse stria at posterior margin of submetapleural carina. Pleural carina complete (Fig. 13); propodeum with posterior transverse and anterior transverse carinae present, lateral longitudinal carina 

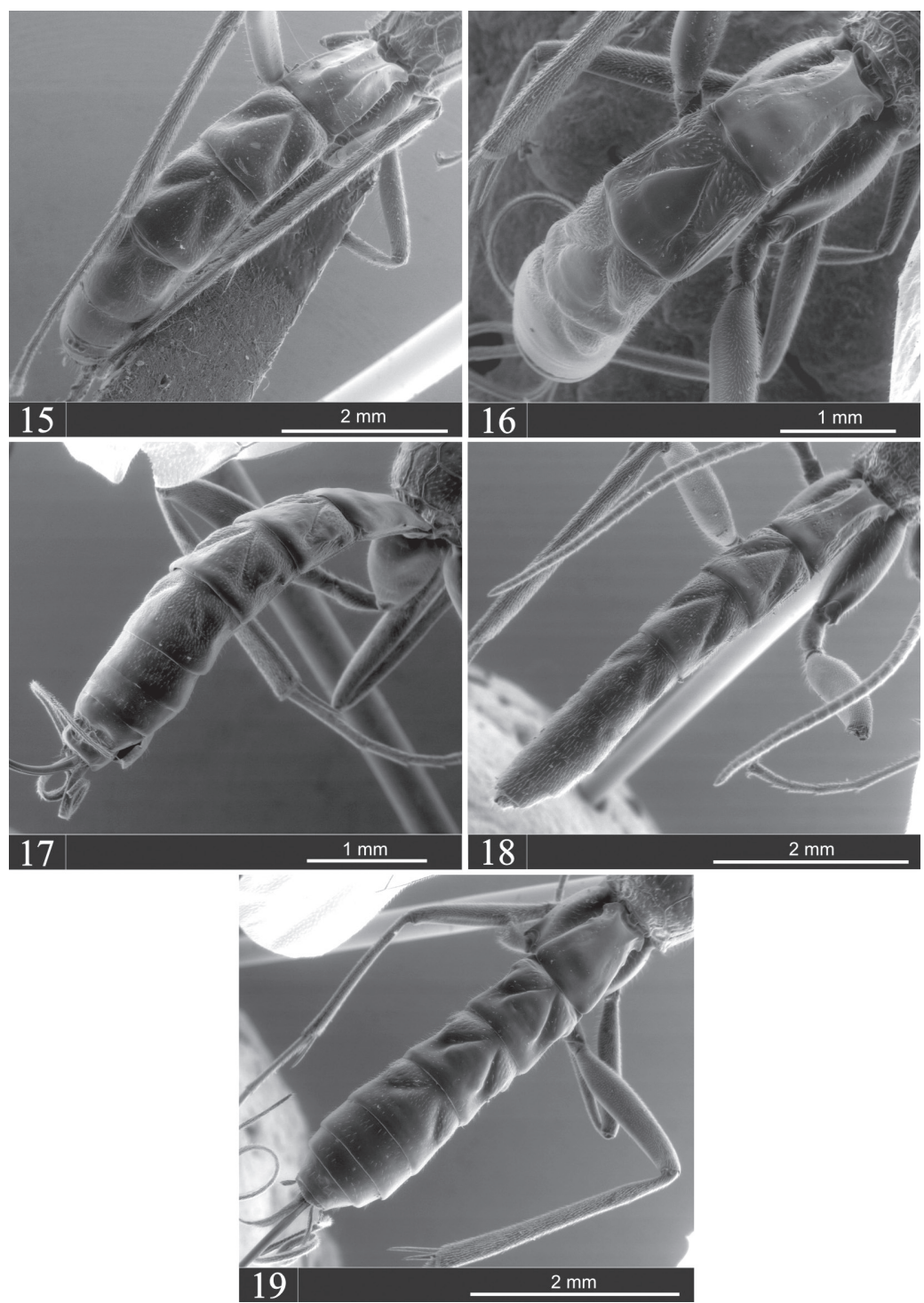

Figs. 15-19. Stereoscan photographs of Sphelodon spp., metasoma; 15, Sphelodon brunicornis n. sp.; 16, Sphelodon boraceiensis n. sp.; 17, Sphelodon zuleidei n. sp.; 18, Sphelodon plaumanni n. sp.; 19, Sphelodon botucatensis n. sp.

present anteriorly until spiracle level, lateromedian longitudinal carina present anteriorly until joining anterior transverse carina (Fig. 13). Fore tibia with spur normally developed, $2.9 \mathrm{x}$ as long as breadth of tibia; mid tibia without conspicuous denticles on outer surface, and with spurs nearly equal, longer $1.1 \mathrm{x}$ length of shorter. Fore wing with abscissa of
$\mathrm{Cu} 1$ between $1 \mathrm{~m}-\mathrm{cu}$ and $\mathrm{Cu} 1 \mathrm{a} 2.0 \mathrm{x}$ as long as $C u 1 b$; hind wing with length of abscissa of $C u 1$ between $M$ and $c u-a 0.6 \mathrm{x}$ as long as combined lengths of this vein and $c u-a$. Metasoma (Fig. 18) with tergite I smooth with some small setiferous punctures, with lateromedian longitudinal carinae very weak, in dorsal view with vestiges present until 0.83 of length; tergite I 

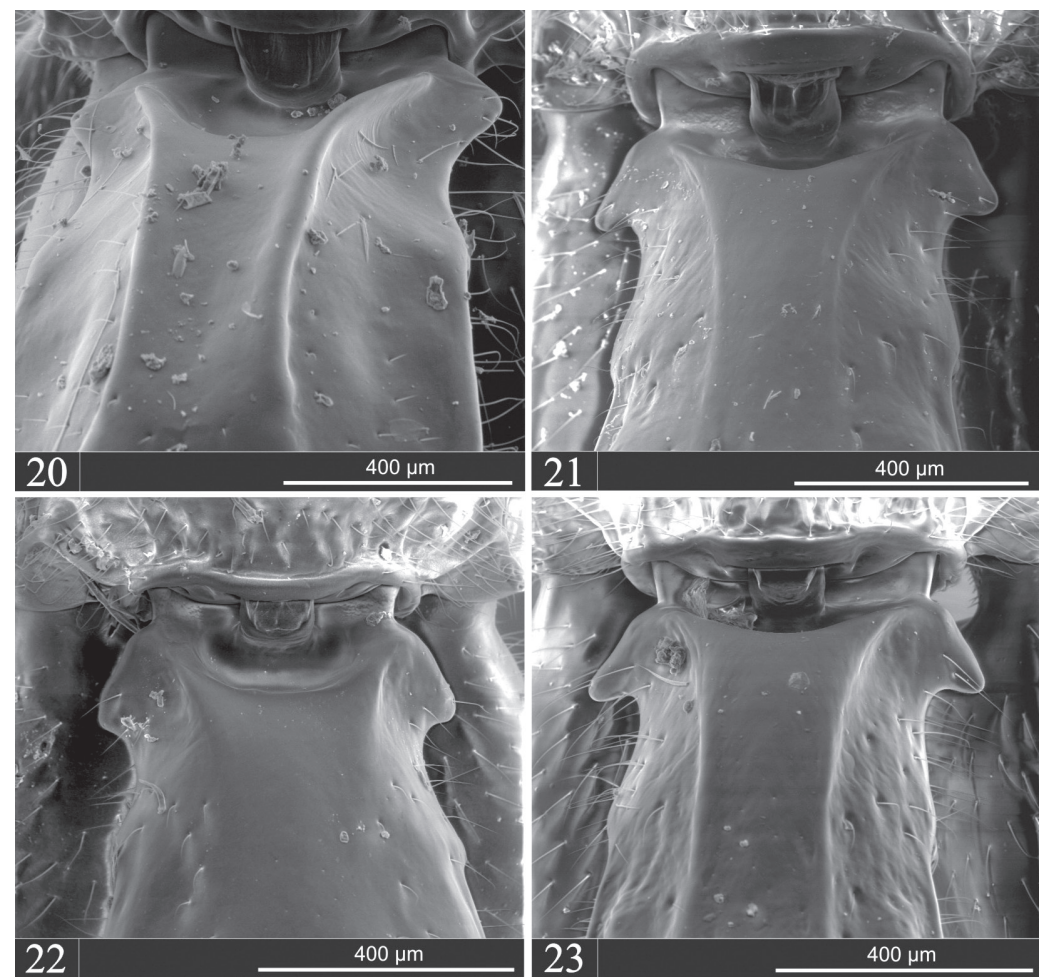

Figs. 20-23. Stereoscan photographs of Sphelodon spp., tergite 1; 20, Sphelodon brunicornis n. sp.; 21, Sphelodon boraceiensis n. sp.; 22, Sphelodon botucatensis n. sp.; 23, Sphelodon plaumanni n. sp.

in lateral view with spiracle positioned anterior to centre, about 0.3 of way along, base with a sharp lateral tooth, apex pointing down (Fig. 23 ); tergite II 1.2 as long as posteriorly broad, with oblique grooves strongly impressed, with some few sparse setiferous punctures in central triangular and lateral areas; tergites III-IV similar though the latter with the oblique grooves weak and with more setiferous punctures than tergite III.

Coloration: Head: Face and clypeus dull yellow with apex brown ferruginous, vertex brown ferruginous, with two yellow spots parallel to ocelli close to eyes, ocelli dark orange, frons mostly brown ferruginous with two lateral strips close to eyes, eyes brown with black spots; scape and pedicel ventrally yellow, dorsally yellow infuscate. Flagellomere 1 brown, outer side with orange strip; flagellomeres 2-12 brown, flagellomere 13 mostly yellow; flagellomeres 14-22 yellow; flagellomeres 23+ brown. Gena dorsally ferruginous brown, ventrally yellow. Maxillary and labial palps orange. Mesosoma orange; propleuron, mesopleuron and metapleuron light orange. Wings hyaline with pterostigma brown. Fore legs orange, mid legs orange with tarsus brown; hind legs, coxa, trochanter, trochantellus, femur orange, tibia mostly orange with apex ferruginous, tarsus mostly yellow, tarsomere 1 with basal half ferruginous, tarsomere 5 ferruginous. Metasoma with tergites I-III dark orange, tergites IV+ ferruginous.

Holotype: Male. BRASIL: Santa Catarina, Nova Teutônia, 52 W 25'5127', 27 S 09'49”, IX/1967 F. Plaumann leg. (UFPR). 
Etymology: This species is named in honour of F. Plaumann, who collected the one known specimen.

\section{Sphelodon zuleidei Herrera n. sp.}

(Figs. 5, 6, 7, 12, 17)

Diagnosis: This species differs from $S$. boraceiensis, S. plaumanni, S. guanacastensis, $S$. phoxopteridis, and S. ugaldei in propodeal characteristics. In these species the area superomedia is not delineated. Also, if compared with $S$. guanacastensis it differs in mesopleuron characteristics. It resembles $S$. annulicornis, S. brunicornis, $S$. botucatensis and $S$. wardae in having a completely delineated area superomedia (Fig. 12) but this species differs from $S$. annulicornis and $S$. botucatensis in the color pattern (e.g. mesoscutum black in $S$. annulicornis and orange in S. zuleidei $\mathrm{n}$. sp., propodeum mostly half red and half yellow in $S$. botucatensis and almost half black ferruginous in $S$. zuleidei); it differs from $S$. wardae in the color pattern and epomia characteristics (in dorsal view with upper end of epomia forming a distinct tubercle in $S$. wardae, not tuberculate in $S$. zuleidei), and from S. brunicornis in having a median white band on the flagellum (Fig. 5). This species differs from the species $S$. beameri and $S$. concolor in propodeal characteristics (with an enclosed area superomedia in the neotropical species and without an enclosed in the nearctic ones). It differs from $S$. nomene in the color pattern (e.g. metasoma black with transverse yellow bands and flagellomeres 9-20 white in $S$. zuleidei and metasoma mostly tawny-rufous and flagellomeres 11 or 12-17 pale yellow in $S$. nomene).

Female: Fore wing length $5.6 \mathrm{~mm}$; hind wing length $4.0 \mathrm{~mm}$. Clypeus $1.4 \mathrm{x}$ as broad as long; lower face very weak convex and smooth; malar space 1.0x as long as basal mandibular width; frons weakly concave and smooth; occipital carina absent (Fig. 6); head in dorsal view with gena rounded behind eyes. Antenna with 44 flagellomeres. Pronotum long, not swollen above epomia, epomia itself strong and long, but not reaching upper margin of pronotum; mesoscutum punctulate with setae, laterally with punctures finer and weaker; notauli quite strongly impressed anteriorly; mesopleuron mostly smooth, with some setiferous punctures specially at anterior margin; epicnemial carina rather straight, not reaching anterior margin of mesopleuron and exceeding the level of lower corner of pronotum; sternal part of mesothorax 1.5x as long as mid coxa. Metapleuron with some sparse, fine punctures with setae and with carina from posterior margin of submetapleural carina to apical margin of metapleuron. Pleural carina complete; propodeum with dorsal carinae more or less complete, delineating enclosed area superomedia; lateral longitudinal carina incomplete (only present anteriorly until spiracle level). Fore tibia with spur normally developed, $1.8 \mathrm{x}$ as long as breadth of tibia; mid tibia without conspicuous denticles on outer surface, spurs nearly equal, longer $1.2 \mathrm{x}$ length of shorter. Fore wing with abscissa of $C u 1$ between $1 m-c u$ and $C u 1 \mathrm{a} 1.1 \mathrm{x}$ as long as $C u 1 \mathrm{~b}$; hind wing with length of abscissa of $C u 1$ between $M$ and $c u-a$ $0.6 \mathrm{x}$ as long as combined lengths of this vein and $c u-a$. Metasoma (Fig. 17) with tergite I smooth, with lateromedian longitudinal carinae weak, present on anterior 0.3 , tergite I in lateral view with spiracle positioned anterior to centre, about 0.3 of way along, base with sharp lateral tooth, margin pointing laterally; tergite II 0.9 as long as posteriorly broad, with oblique grooves strongly impressed, with central triangular area smooth and lateral area with some fine sparse punctures, tergite III with oblique grooves strongly impressed, with triangular area with some fine punctures, and lateral area with setiferous punctures strongly all over impressed; tergite IV with oblique grooves weaker, with fine setiferous punctures all over. Ovipositor of moderate length, 1.6x as long as hind tibia.

Coloration: Head: face orange ochre, clypeus orange ochre, mandibles orange ochre with apex red ferrugineous, labial and maxilar palps yellow ochre; vertex and frons black centrally, with margins ochre; occiput black; ocelli 
brown; gena dorsally black, ventrally ochre; scape ventrally brown with margin yellow pedicel ventrally yellow; flagellomeres 1-8 dark brown, flagellomere 9 mostly light brown, flagellomeres 10-20 light brown, flagellomeres 21+ dark brown. Mesosoma, mesoscutum orange, scutellum and dorsellum light orange; pronotum mostly orange with ventral margin yellow; mesopleuron mostly yellow, dorsally orange; metapleuron yellow, with mid anterior black spot. Wings hyaline with pterostigma dark brown and apex of fore wings with weak brown spot. Propodeum ferrugineous, area petiolaris, area posteroexterna, most of area dentipara and area superomedia yellow, area externa mostly orange. Fore legs with coxa, trochanter light orange, trochantellus mostly orange with apical brown spot, femur orange with a basal brown spot, tibia and tarsus orange; mid legs, coxa light orange, trochanter light orange with two basal brown spots, trochantellus mostly brown, femur orange with a basal brown spot, tibia orange, tarsus brown; hind legs with coxa light orange with big black spot at outer side, small dorsal black spot at inner side; trochanter yellow with dark brown spot basally, trochantellus mostly brown, femur mostly orange with basal black spot and longitudinal brown strip at outer side; tibia mostly brown ferruginous with yellow strip at anterior side, tibial spur brown ferruginous, tarsus mostly brown, tarsomere 1 with distal half yellow ochre. Metasoma with tergite I black, anteriorly and posteriorly yellow; tergite II-IV mostly black, with posterior yellow strip; tergite V-VI with first half black, last half yellow, tergite VII yellow, first half ferruginous; tergite VIII ferruginous. Ovipositor orange. Ovipositor sheath dark brown.

Holotype: Female, BRASIL, RJ, Teresópolis, Parque Nacional Serra dos Orgãos 42 W 56', 22 S 26' Armadilha Malaise 43 31.X-05. XI.2004 ALBG Peronti e equipe col. (UFES)

Etymology: This species is named in honour of our colleague Zuleide Ramiro.

\section{Key to Sphelodon species occurring in the Neotropical Region (adapted from Gauld et al. 2002)}

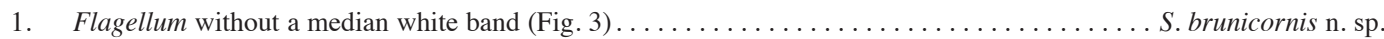

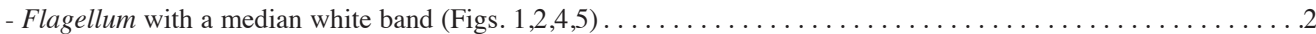

2. Metasoma pale yellowish brown or orange, sometimes with transverse pale yellow bands on some tergites

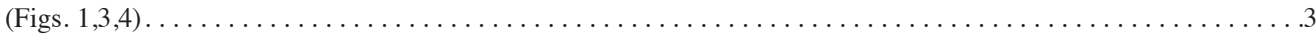
- Metasoma black or dark brown with transverse white or pale yellowish bands (Figs. 2,5) . . . . . . . . . . .7

3. Mesopleuron closely and coarsely punctate (Fig. 24) ................. guanacastensis Godoy \& Gauld

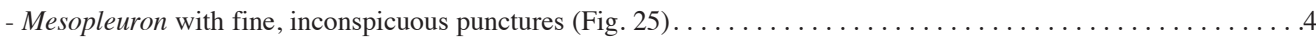

4. Pronotum in dorsal view with upper end of epomia forming a distinct tubercle (Fig. 26) . S. wardae Godoy \& Gauld

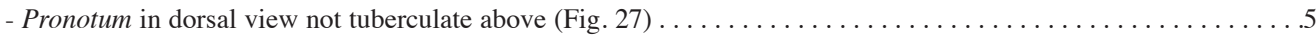

5. Base of tergite I with margin of lateral tooth pointing laterally (Fig. 22); gena and vertex yellow (only the interocellar area black $) \ldots \ldots \ldots \ldots \ldots \ldots \ldots \ldots \ldots \ldots \ldots \ldots \ldots \ldots \ldots \ldots \ldots \ldots \ldots \ldots \ldots \ldots \ldots \ldots \ldots \ldots \ldots \ldots \ldots$ Godoy \& Gauld - Base of tergite I with margin of lateral tooth pointing down (Fig. 21); gena and vertex mostly black . . . . . . .6

6. Propodeum with anterior and posterior transverse carinae normally developed; the latter rather straight (Fig. 13).

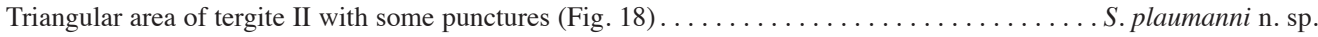
- Propodeum with anterior transverse carina, complete and strong and posterior transverse carina complete, strong and

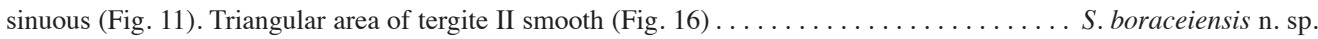

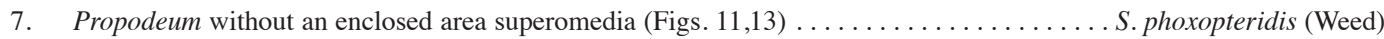

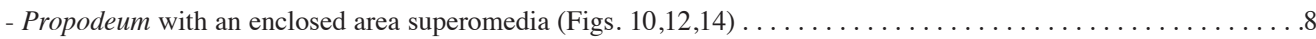

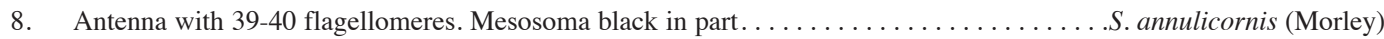
- Antenna with 43 or more flagellomeres. Mesosoma partly orange or red $\ldots \ldots \ldots \ldots \ldots \ldots \ldots \ldots \ldots$ 
9. Lateral area of tergite II with some sparse punctures (Fig. 17). Propodeum with area petiolaris, area posteroexterna and most of area dentipara and area superomedia yellow; area externa mostly orange, rest of propodeum dark ferrugineous;

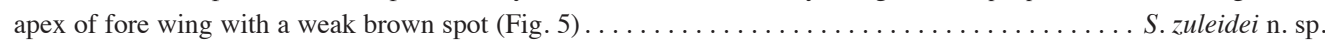
- Lateral area of tergite II different (smooth with some pubescence) (Fig. 19). Propodeum mostly red with yellow spots in area dentipara; fore wing hyaline (Fig. 5)

S. botucatensis n. sp.
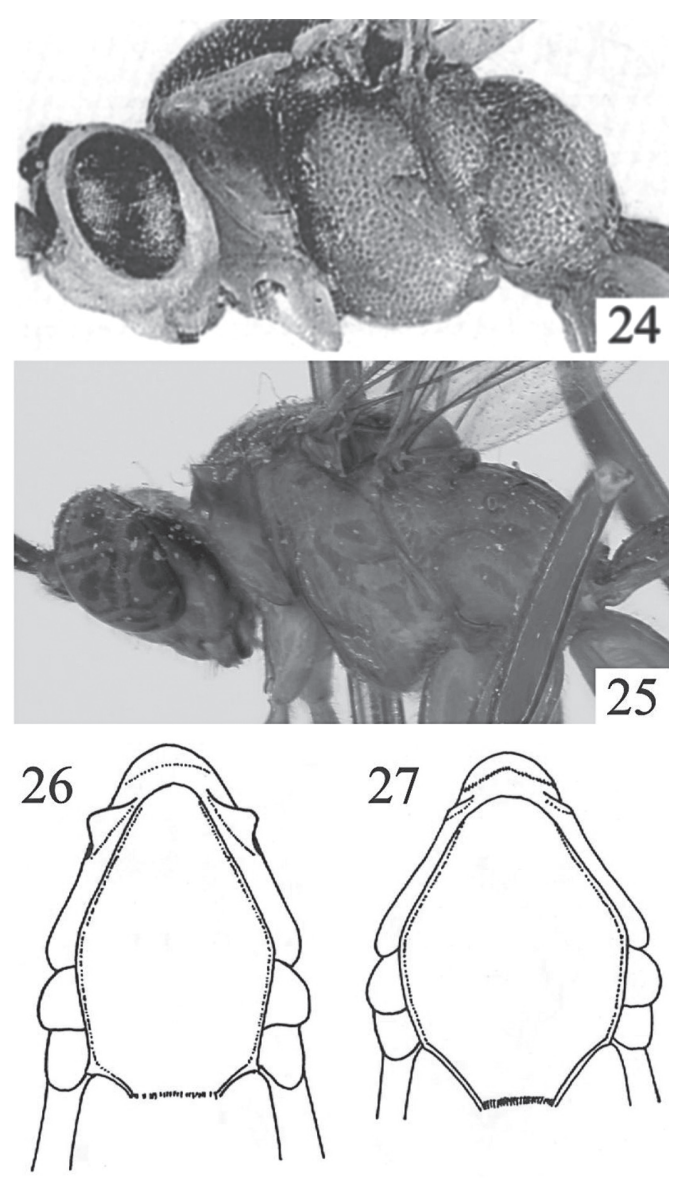

Figs. 24-27. Sphelodon spp. Figs. 24-25. Photographs of head and mesosoma, lateral; 24, S. guanacastensis (Taken from Gauld et al. (2002) with permission of the authors); 25, S. wardae. Figs. 26-27. Taken from Gauld et al. (2002) with permission of the authors. Anterior part of mesosoma, dorsal; 26, S. wardae; 27, S. ugaldei.

\section{ACKNOWLEDGMENTS}

The authors acknowledge the financial assistance of $\mathrm{CNPq}$ (Conselho Nacional de Desenvolvimento Científico e Tecnológico), FAPESP (Fundação de Amparo à Pesquisa do Estado de São Paulo, Programa Biota) and HYMPAR/SUDESTE (INCT-Instituto Nacional dos Hymenoptera Parasitóides da Região Sudeste Brasileira). We are indebted to Dr. David Wahl (American Entomological Institute) and Dr. Carolina Godoy for giving us permission to use some images extracted from the book: "The Ichneumonidae of Costa Rica 4 " in this paper. Also, special thanks to Luciana Bueno dos Reis Fernandes for taking and editing the photos and improving the text, Dr. Gavin Broad and Dr. Dmitry Dmitriev for imaging the Sphelodon holotypes from the British Museum of Natural History collection and Illinois Natural History Survey respectively, and to the three reviewers who decidedly helped to improve this article.

\section{RESUMEN}

La familia de avispas parasitoides Ichneumonidae incluye aproximadamente 37 subfamilias a nivel mundial, una de ellas, Banchinae es un grupo cosmopolita con tres tribos: Atrophini, Banchini y Glyptini: los miembros de esta tribu presentan surcos oblicuos en los tergitos II-IV, una muesca dorsal sub-apical en el ovipositor y una impresión media apical en la placa subgenital; este grupo incluye los géneros Levibasis, Teleutaea, Glypta, Zaglyptomorpha y Sphelodon en la región Neotropical. El género mencionado anteriormente se diferencia de los demás por la presencia de un diente baso-lateral en el primer tergito abdominal, y cuenta con 8 especies descritas, sin embargo como Costa Rica es el único país de la región donde se ha realizado un levantamiento riguroso de este grupo, es muy probable que muchas especies no hayan sido descritas todavía. De este género, sólo existe una especie registrada para Brasil $(S$. annulicornis). Este trabajo se basó principalmente en material obtenido en calidad de préstamo de las colecciones entomológicas más reconocidas del Sur y del Sudeste de Brasil, provenientes de localidades correspondientes a 17 de los 27 estados que existen en este país, aunque la mayoría de ejemplares $(70.3 \%)$ fueron recolectados en el estado de São Paulo. Aproximadamente 3000 ejemplares de la subfamilia fueron examinados, 29 pertenecientes al género de la tribu Glyptini Sphelodon. El formato de descripción de las especies es básicamente el mismo expuesto por 
Gauld et al. (2002); las microfotografías que ilustran los detalles de las especies nuevas se realizaron en un microscopio electrónico de barrido (SEM), en el modo de bajo vacío (los ejemplares no fueron recubiertos). Se describen e ilustran cinco especies nuevas del género Sphelodon, una de ellas, S. Brunicornis, se distingue de las otras especies descritas del género porque no presenta un anillo medio en el flagelo. Se propone una clave de identificación para las especies neotropicales.

Palabras clave: avispas, clave de identificación, Glyptini, Suramérica, taxonomía.

\section{REFERENCES}

Dasch, C.E. 1988. Ichneumon-flies of America north of Mexico 9. Tribe Glyptini. Mem. Am. Ent. Inst. 43: $1-644$.

Gauld, I.D. 1991. The Ichneumonidae of Costa Rica 1. Mem. Am. Ent. Inst. 47: 1-589.

Gauld, I.D., C. Godoy, R. Sithole \& G.J. Ugalde. 2002. The Ichneumonidae of Costa Rica 4. Mem. Am. Ent. Inst. 66: 1-768.

Morley, C. 1914. A revision of the Ichneumonidae based on the collection in the British Museum (Natural
History) Part III: Tribes Pimplides and Bassides. British Museum, London, England.

Ruiz, C.E. 2010. Ichneumonidae (Hymenoptera) del Estado de Tamaulipas, Mexico. Serie Avispas parasíticas de plagas y otros insectos. No. 6. Editorial Planea, México.

Ruiz, C.E., D.R. Kasparyan \& J.M.A. Coronado. 2002. Ichneumonidae, p. 631-646. In J. Llorente \& J.J. Morrone (eds.). Biodiversidad, taxonomía y biogeografía de artrópodos de México, Vol. III. UNAMCONABIO, México.

Townes, H. 1970. Genera of Ichneumonidae 3. Mem. Am. Ent. Inst. 13: 1-307.

Townes, H. \& M. Townes. 1966. A catalogue and reclassification of Neotropic Ichneumonidae. Mem. Am. Ent. Inst. 8: 1-367.

Yu, D. \& K. Horstmann. 1998. A catalogue of world Ichneumonidae (Hymenoptera). Mem. Am. Ent. Inst. 58: 1-1558.

Yu, D.S., C. Van Achterberg \& K. Horstmann. 2005. World Ichneumonoidea 2004, taxonomy, biology, morphology and distribution. CD/DVD, Taxapad, Vancouver, Canada. 
